\title{
Klippel Feil Syndrome: A Case Report
}

\author{
Dhananjoy Das ${ }^{1 *}$ \\ M A Chowdhury (Arzu) ${ }^{1}$ \\ S M Zafar Hossain ${ }^{1}$
}

'Autism and Child Development Centre \& Child Neurology Unit

Chattogram Maa Shishu-O-Shishu Hospital Medical College Chattogram, Bangladesh.
*Correspondence to:

\section{Dr. Dhananjoy Das}

Assistant Professor

Autism and Child Development Centre \&

Child Neurology Unit

Chattogram Maa Shishu-O-Shishu Hospital Medical College Chattogram, Bangladesh

Mobile : +8801819859016

Email: dhananjoyjoly@gmail.com

Date of Submission : $\quad 09.10 .2019$

Date of Acceptance : 10.12 .2020

www.banglajol.info/index.php/CMOSHMCJ

\begin{abstract}
Klippel-Feil Syndrome (KFS) is a complex syndrome comprises of classical clinical triad of short neck, limitation of head and neck movements and low posterior hairline. This syndrome is resulting from failure of the normal segmentation of cervical vertebra.

In this present case in addition to classical clinical triad we have found short stature, scoliosis at cervico- dorsal junction and sprengel deformity of the shoulder. We didn't find any association of hearing impairment, congenital heart disease and renal abnormalities. There was no any neurological deficit and normal school performance.
\end{abstract}

Patient with KFS usually have good prognosis if cardiopulmonary, genitourinary, auditory problems are identified and treated early.

Key words: Congenital; Fusion; Klippel-Feil syndrome; Cervical vertebrae.

\section{INTRODUCTION}

Klippel-Feil Syndrome (KFS) was first discovered by Maurice Klippel and Andre Feil in $1912^{1}$. KFS is a complex syndrome comprises of classical clinical triad of short neck, limitation of head and neck movements (Especially lateral bending) and low posterior hairline ${ }^{2}$. In $50 \%$ cases have all three component of this syndrome. It occurs in 1 of every 42,000 births and $60 \%$ cases are Female ${ }^{2}$. KF syndrome is group of deformities that result due to failure of the normal segmentation and fusion processes of mesodermal somites, which occurs between the third and seventh week of embryonic life $\mathrm{f}^{3,4}$. Almost all cases of this syndrome occur sporadically; nevertheless, close evaluation of the immediate family is recommended ${ }^{3,4}$. It is associated with several defects, such as deafness, either conductive or neural, congenital heart defects, the most common being a ventricular septal defect, mental deficiency, cleft palate, anomalies of kidneys and rib, the Sprengel quence (Elevated scapula), hemivertabrae, basilar impression, platybasia, spina bifida, torticollis, and scoliosis or kyphosis. Patients with KFS may exhibit a smaller lower third of the face and facial asymmetry with no dental implications ${ }^{5}$.

Usually in Sprengel deformity there is loss of abduction \& forward flexion after 90 deg. In $30 \%$ of cases with Sprengel deformity, the scapula is bound to cervical spine by fibrous tissue, cartilage or an omovertebra bone which restrict abduction of shoulder after 90 degree. The differential diagnosis of this condition includes spondylocostal dysostoses, Poland syndrome, spondyloepiphysial dysplasia and short-rib polydactyl syndromes ${ }^{6}$.

The bony malformations present in patients with KFS may entrap and damage the brain and spinal cord. Disorders of the lower vertebral region may become symptomatic during the rapid growth of adolescence or in adult life.

In this report, we present clinical and radiographic findings in an 8-year-old girl with KFS. 


\section{CASE REPORT}

A 7 years 6 month old girl attended Child Neurology OPD of Autism and child development Centre of Chattagram Maa Shishu-O-General Hospital with the complaints of short stature and not growing well as comparison with other peers. There was no history of consanguinity. She was delivered normally at term at local clinic and cried immediately after birth. There was no antenatal history of fever, hypertension and taking any drug. There was no history of any significant event during pregnancy. She was not having any history trauma, or infection. She has completed all her vaccination. There was no significant family history. Her developmental milestones were appropriate for her age, sitting at eight month, standing at twelve month, walking at fifteen month. Her school performance is satisfactory as per her school teacher. She is independence in her all daily activities.

On examination she is cooperative with normal body built and short in height. She has short neck and low posterior hair line. She can perform full flexion of neck, partly extension, rotation, but there is limitation of lateral bending of cervical spine. Both scapulas are elevated. Abduction of both shoulder joints is limited up to 90 degrees. No neurological deficits are identified. Other system examination revealed no abnormalities. Her height is $105 \mathrm{~cm}$, height for age $\mathrm{Z}$ score $-3.4 \mathrm{SD}$, Upper segment $46 \mathrm{~cm}$, lower segment $59 \mathrm{~cm}$, upper segment lower segment ratio is 0.7 : 1 . Her weight is $18 \mathrm{~kg}$, weight for age $\mathrm{Z}$ score is 1SD. Radiological examination of cervical spine and both shoulder joint revealed segmentation failure at multiple levels of cervical and upper thoracic spines. There is interbody fusions at C3. C4,C5.C6, C7.D1, D2 to D6. Clefting seen in C7, D5. There is odontoid hypoplasia with suspected axial subluxation of atlanto-axial joint are seen. There is dextroscoliosis at cervico-dorsal junction and fusion of right upper 3 ribs and left $1^{\text {st }}$ and $2^{\text {nd }}$ ribs. Image of shoulder joints show elevated high riding left scapula suggestive of sprengel shoulder. The girl was referred to Senior Plastic Orthopedic Surgeon \& was advised for conservative management to begin with. As our case was not having any neurological or any other systemic involvement she was advised exercises of neck \& left shoulder 5 to 6 times a day. Corrective cervical collar was prescribed and the technique of manual traction of cervical spine was explained \& demonstrated to her father. Prognosis was explained in detail.

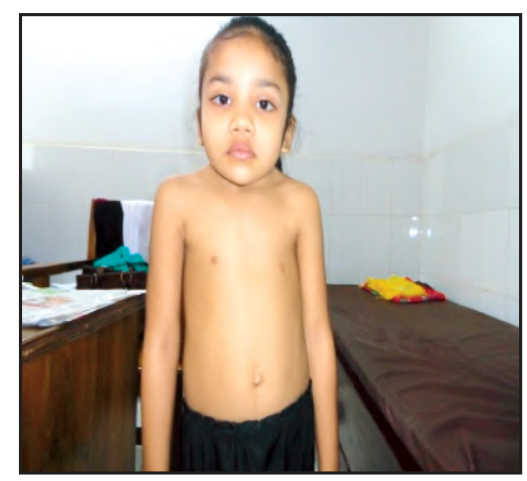

Figure 1 : Clinical photograph showing short neck

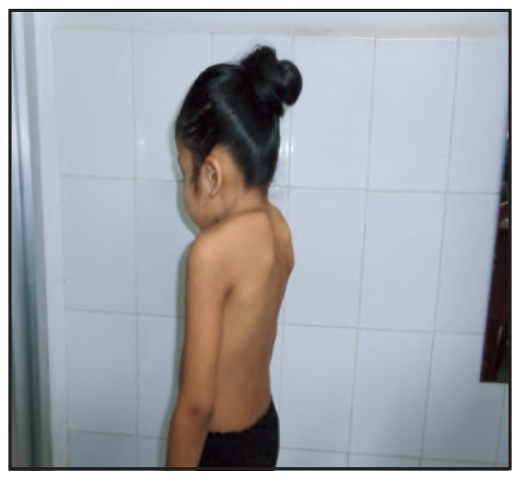

Figure 2 : Clinical photograph showing sprengel shoulder

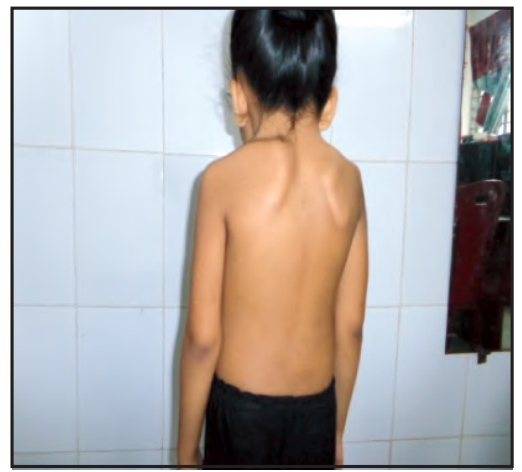

Figure 3 : Clinical photograph showing low posterior hairine and elevated left scapula

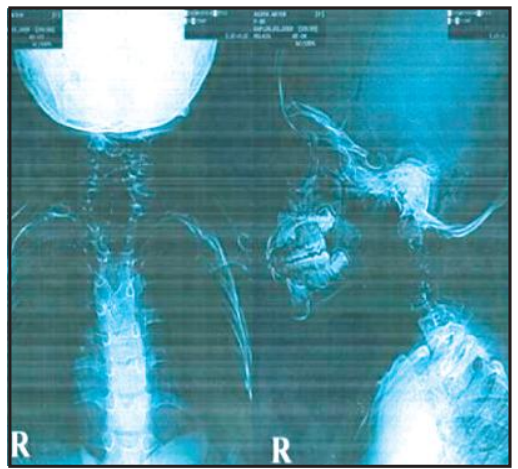

Figure 3 : Radiological examination of cervical spine revealed interbody fusions at C3.C4, C5.C6, C7.D1, D2 to D6, fusion of neural arches $\mathrm{C} 3$ to $\mathrm{C} 7$, clefting C7, D5. hypoplasia odontoid with suspected axial subluxation of atlanto-axial joint, dextroscolosis at cervico-dorsal junction, fusion of (R) upper 3 ribs and $(\mathrm{L}) 1^{\text {st }} \& 2^{\text {nd }}$ ribs

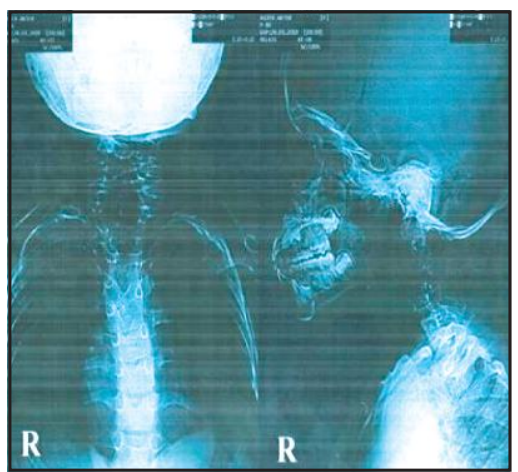

Figure 4 : Radiological examination of chest and both shoulder joint revealed elevated high riding (Left) scapula 


\section{DISCUSSION}

Klippel-Feil Syndrome (KFS) refers to failure of Cervical vertebral segmentation resulting from failure of the normal segmentation and fusion processes of the mesodermal somites, which occur between the third and seventh week of embryonic development ${ }^{3,4}$. According to Gunderson and others there are 3 types of cervical vertebral fusion defect related to Klippel-Feil anomalies ${ }^{7}$ :

Type-I massive fusion of many cervical and upper thoracic vertebrae into bony blocks

Type-II fusion of only 1 or 2 interspaces, usually C2-C3 or C5C6, but there can be intrafamilial variability

Type III-both cervical fusion and lower thoracic or lumbar fusion, often associated with multiple organ anomalies and subsequent neurologic compromise.

A fourth type of Klippel-Feil anomaly has been suggested to be associated with sacral agenesis ${ }^{5}$. This patient presented with a short neck, limited neck movements and a low-set posterior hairline. Radiologically there are interbody fusions at C3. C4, C5.C6, C7.D1 and D2 to D6. With these features, this present case fits the type II category of KFS. Klippel-Feil syndrome with this category may associate with partial or complete conductive hearing impairment, congenital heart disease, underdeveloped low-set ears and facial asymmetry. These findings are not consistent with our patient. However because of the high incidence of hearing loss in patients with KFS, audiologic examinations are recommended. Thorough orthodontic evaluation is also very important in patient with KFS as these patients might have sub mucous cleft palate and congenitally absence teeth ${ }^{8}$.

To the best of our knowledge, fusion of right upper 3 ribs and left $1^{\text {st }}$ and $2^{\text {nd }}$ rib has not yet been reported with KFS. Scoliosis is the most common associated abnormality with KFS, was seen in the case presented and it is found at cervicodorsal junction.

Moreover to the best of our knowledge Odontoid hypoplasia and subluxation of atlanto axial joint has not been yet reported with KFS. It is one of the most frightening finding as cervical cord, brain stem are at risk of injury.

In addition to scoliosis, the presence of a Sprengel deformity was identified. It is the second most common deformity associated with KFS, was first described by Eulenberg in $1863^{9,10}$. The accepted cosmetic classification of Sprengel deformity, the Cavendish classification, was proposed in $1972^{11}$.

The Cavendish classification system proposed grades based on the deformity. Grade 1 is described as a very mild deformity that is not noticeable when the patient is dressed. Grade 2 is described as a mild deformity that is visible as

a lump in the web of the neck when the patient is dressed. Grade 3 is a moderate deformity described as an easily visible deformity with the shoulder joint elevated 2-5 centimeters. Grade 4 is a severe deformity with shoulder joint elevation greater than 5 centimeters or evidence of the superior angle of the scapula near the occiput with or without webbing. Although this classification does not consider function, it is utilized in the management of the deformity for objective differentiation when surgical intervention is necessitated to correct both appearance and function.

In the case of our patient, the left shoulder was elevated and clinically consistent with Grade 2 Sprengel deformity according to the Cavendish classification.

No surgical intervention, such as disc arthroplasty or fusion of unstable adjacent cervical spine levels, was indicated for our patient, since neurologic symptoms to suggest radiculopathy or myelopathy were not evident. However, Type III KFS patients do have increased risk of developing radiculopathic or myelopathic symptoms when compared to Type I and II patients ${ }^{12}$. Typical age of onset of spine related neurologic symptoms is between 10 and 11 years of age for KFS patients when the disorder is identified in childhood. However, patients with milder forms of KFS not detected in childhood can present with neurologic symptoms into their $40 \mathrm{~s}^{13,14}$. For this reason, the patient was encouraged to continue routine follow-up to evaluate for future development of neurological deficit.

The treatment for Sprengel deformity depends on the severity of the abnormality. For mild deformities classified as Cavendish Grades 1 and 2, nonsurgical options including physical therapy, stretching, and continued observation are most beneficial for the prevention of torticollis and decreased range of motion. Moderate and severe deformities that fall into the higher Cavendish classification grades are candidates for surgical intervention. There are two of the most popular procedures are the Green's and Woodward procedures.

Patient with KFS usually have good prognosis if cardiopulmonary, genitourinary, auditory problems are identified and treated early ${ }^{16}$. In anomalies of occipito-cervical passage, high morbidity and mortality rates have been frightening, as cervical cord and brain stem are very close to each other ${ }^{17}$.

In our case no cardiopulmonary, genitourinary, auditory and neurological problems are identified. The present case has classical triad low posterior hairline, short neck \& limited cervical range of motion.

\section{CONCLUSION}

Important consideration in the work up of Klippel Feil syndrome should be to identify other systemic anomalies associated with it for better management and early rehabilitation.

\section{DISCLOSURE}

All the authors declared no competing interest. 


\section{REFERENCES}

1. Jones KL. Smith's recognizable patterns of human malformation. 5th ed. Philadelphia: WB Saunders Company. 1997.

2. Stephen R Pledger. Cervical Spine Disease. Ortho Secrets, 3rd Ed. 2003.

3. Vaidyanathan S, Hughes PL, Soni BM, Singh G, Sett P. Klippel-Feil syndrome-the risk of cervical spinal cord injury: A case report. BMC Fam Pract. 2002;3:6.

4. Boraz RA, Irwin DH, Van Blarcom C, The dental rehabilitation of a patient of klippel-feil syndrome and sprengel's deformity. Spec Care Dentist. 1986; 6(1):22-24.

5. Rimoin DL, Connor JM, Pyeritz RE. Emery and Rimoin's principles and practice of medical genetics. 3rd ed. New York: Churchill Livingstone. 1996.

6. Paul W Esposito and Brain E Brighman. Miscellaneus Congenital Disorders. Ortho Secrets, 3rd Ed. 2003.

7. Gunderson CH, Greenspan RH, Glaser GH, Lubs HA. The Klippel-Feil syndrome: Genetic and clinical reevaluation of cervical fusion. Medicine (Baltimore) 1967; 46(6):491-512.

8. Hensinger RN, Lang JE, MacEwen GD. Klippel-Feil syndrome. A constellation of associated anomalies. J Bone Joint Surg Am. 1974;56(6):1246-1253

9. R. N. Hensinger, J. E. Lang and G. D. MacEwen. "Klippel-Feil syndrome; A constellation of associated anomalies". Journal of Bone and Joint Surgery, American Volume. 1974;56(6):1246-1253.

10. M. Eulenberg. "Casuistische Mittelheilungen aus dem Gembeite derOrthopadie”. Archiv fuer Klinische Chirurgie. 1863;4:301-311.

11. M. E. Cavendish. "Congenital elevation of the scapula”. Journal of Bone and Joint Surgery, British Volume. 1972;54(3):395-408.

12. D. D. Samartzis, J. Herman, J. P. Lubicky and F. H. Shen. "Classification of congenitally fused cervical patterns in Klippel-Feil patients: Epidemiology and role in the development of cervical spine-related symptoms," Spine. 2006;31(21):E798-E804.

13. A. Reyes-Sanchez, B. Zarate-Kalfopulos and L. M. Rosales-Olivares. "Adjacent segment disease in a patient with Klippel-Feil syndrome and radiculopathy: surgical treatment with two-level disc replacement,” SAS Journal. 2007;1(4):131-134.

14. S. A. Mirhosseini, S. M. M. Mirhosseini, R. Bidaki and A. P. Boshrabadi. "Sprengel deformity and Klippel-Feil syndrome leading to cervical myelopathy presentation in old age. Journal of Research in Medical Sciences. 2013;18(6):526-528.

15. G. Andrault, F. Salmeron, and J. M. Laville. “Green's surgical procedure in Sprengel's deformity: Cosmetic and functional results. Orthopaedics \& Traumatology: Surgery \& Research. 2009;95(5):330-335.

16. Pizzutillo PD, Woods M, Nicholson L, MacEwen GD. Risk factors in Klippel-Feil syndrome. Spine. 1994;19:2110-2116.

17. Disorder of the neck. In: Herring JA, editor. Tachdjian's pediatric orthopaedics. 3rd ed. Philadelphia: W. B. Saunders. 2002;1:173-187. 